\title{
The association between chronic pain and obesity
}

This article was published in the following Dove Press journal:

Journal of Pain Research

14 July 2015

Number of times this article has been viewed

\section{Akiko Okifuji \\ Bradford D Hare}

Pain Research and Management

Center, Department of

Anesthesiology, University of Utah,

Salt Lake City, UT, USA
Correspondence: Akiko Okifuji

Pain Research and Management

Center, Department of Anesthesiology,

University of Utah, 615 Arapeen Drive,

Suite 200, Salt Lake City, UT 84I08, USA

$\mathrm{Tel}+\mathrm{I} 8015857690$

Fax + I 80I 5857694

Email akiko.okifuji@hsc.utah.edu
Abstract: Obesity and pain present serious public health concerns in our society. Evidence strongly suggests that comorbid obesity is common in chronic pain conditions, and pain complaints are common in obese individuals. In this paper, we review the association between obesity and pain in the general population as well as chronic pain patients. We also review the relationship between obesity and pain response to noxious stimulation in animals and humans. Based upon the existing research, we present several potential mechanisms that may link the two phenomena, including mechanical/structural factors, chemical mediators, depression, sleep, and lifestyle. We discuss the clinical implications of obesity and pain, focusing on the effect of weight loss, both surgical and noninvasive, on pain. The literature suggests that the two conditions are significant comorbidities, adversely impacting each other. The nature of the relationship however is not likely to be direct, but many interacting factors appear to contribute. Weight loss for obese pain patients appears to be an important aspect of overall pain rehabilitation, although more efforts are needed to determine strategies to maintain long-term benefit.

Keywords: comorbidity, BMI, chronic pain, obesity, lifestyle, weight loss, headaches, fibromyalgia

\section{Introduction}

Obesity is a condition of abnormal or excessive fat accumulation in adipose tissue. ${ }^{1}$ Obesity is usually defined by using weight and height to calculate "body mass index" (BMI). Normal weight status ranges from $18.5 \mathrm{~kg} / \mathrm{m}^{2}$ to $24.9 \mathrm{~kg} / \mathrm{m}^{2}$, and overweight status ranges from $25 \mathrm{~kg} / \mathrm{m}^{2}$ to $29.9 \mathrm{~kg} / \mathrm{m}^{2}$ of BMI. A BMI that is greater than $30 \mathrm{~kg} / \mathrm{m}^{2}$ is considered to reflect obesity. The obese category is further subdivided into class I $\left(30-34.9 \mathrm{~kg} / \mathrm{m}^{2}\right)$, class II $\left(35-39.9 \mathrm{~kg} / \mathrm{m}^{2}\right)$, and class III $\left(\geq 40 \mathrm{~kg} / \mathrm{m}^{2}\right)$. A BMI that is greater than $40 \mathrm{~kg} / \mathrm{m}^{2}$ is considered as "morbid" obesity. According to the recent estimates by the World Health Organization (WHO), 39\% and 13\% of adults worldwide were overweight and obese in 2014, respectively. ${ }^{2}$ In the USA, the rate of obesity seems to far exceed the world average. A recent large-scale study with over 9,000 participants found that $69 \%$ of their adults were either overweight or obese and $35 \%$ were in the obese category. ${ }^{3}$ It is well documented that obesity has high morbidity: obesity presents a significant risk factor for a range of medical problems, including cardiovascular diseases, cancer, and diabetes. ${ }^{4}$ The health care costs for obesity-related conditions are estimated to be over $\$ 200$ billion in 2005 dollars for US adults. ${ }^{5}$

Accumulating evidence strongly suggests that pain and obesity are significantly related to each other, and obesity is potentially a marker of greater functional and psychological complications of chronic pain. In this paper, we review the association 
of obesity and pain, possible mechanisms underlying the relationship, and clinical implications of comorbid obesity in pain.

\section{Obesity and pain complaints}

A large volume of evidence exists pointing to the concurrence of obesity and pain complaints. Based upon the electronic medical record data in the Veterans Health Administration, obesity was significantly and consistently associated with persistent pain complaints (odds ratio $[\mathrm{OR}]=1.89,95 \%$ confidence interval $[\mathrm{CI}], 1.56-2.30) .{ }^{6}$ Similar results have been shown in adolescents and children as well; obesity is significantly associated with the presence and extent of pain complaints in the young. ${ }^{7-9}$ Similarly, a multistate study ${ }^{10}$ showed the incremental relationship between obesity and pain, that is, pain complaint became more prevalent as BMI status rose. In this study, the likelihood of morbidly obese people having a pain complaint was four times higher than those who were not obese. The prevalence of low back pain increases as BMI rises; less than 3\% of people in the normal BMI range reported low back pain in the past 3 months, whereas $7.7 \%$ of obese and $11.6 \%$ of morbidly obese individuals reported low back pain in the US cohort study of 6,796 adults. ${ }^{11} \mathrm{~A}$ large-scale survey with over 1 million people in the USA ${ }^{12}$ demonstrated a linear increment of chronic pain cases as BMI increases. Relative to normal weight people, overweight people reported $20 \%$ greater rates of recurring pain, and the rates go up to $68 \%$ for people with class I obesity, $136 \%$ for people with class II obesity, and $254 \%$ for people with morbid obesity.

There is ample evidence that obesity and chronic pain coexist. A community study ${ }^{13}$ reported that obesity was associated with various pain diagnoses including low back pain, headaches, fibromyalgia/chronic widespread pain, and abdominal pain. Severe obesity in the elderly doubles the likelihood of having chronic pain. ${ }^{14}$ A systematic review ${ }^{15}$ concludes that obese people are at a greater risk of having headaches, particularly chronic headaches. Similarly, obesity appears to be a risk factor for developing abdominal pain, ${ }^{16}$ pelvic pain, ${ }^{17}$ and neuropathic pain. ${ }^{18,19}$

Conversely, obesity is common in people with chronic pain. People reporting widespread pain tend to have greater total fat mass and less total lean mass than those not reporting pain. ${ }^{20}$ Yunus et $\mathrm{al}^{21}$ showed that over $60 \%$ of women with fibromyalgia in their study were at least overweight, with $32.2 \%$ in the obese range. Another study showed higher mean BMI in fibromyalgia patients compared to the pain-free individuals. ${ }^{22}$ In our previous studies, up to $58 \%$ of the women with fibromyalgia were obese..$^{23,24}$ Similarly, Neumann et a ${ }^{25}$ reported that out of 550 women with fibromyalgia, $28 \%$ were overweight, and $45 \%$ were obese. Loevinger et $\mathrm{al}^{26}$ reported that chronic pain was associated with larger waist circumference and higher low-density lipoprotein cholesterol and triglyceride, linking chronic pain with an increased risk of metabolic syndrome.

The association between joint pain and obesity is also well documented. Osteoarthritis (OA) is one of the most prevalent musculoskeletal conditions with the estimated 27 million afflicted adults in the USA. ${ }^{27}$ Numerous studies suggest that obesity is related to the presence, progression, and severity of OA..$^{28-31}$ Perhaps not surprisingly, given the aging population and rise in obesity, the number of surgical interventions for $\mathrm{OA}$ is on the rise. For example, the number of total knee replacement has increased by $134 \%$ from 1999 to $2008 .{ }^{32}$ Obesity may also be a leading factor for needing surgical intervention for OA patients. The relative risk of having total hip or knee replacement increases as BMI increases, ${ }^{33}$ for people with morbid obesity ( $\mathrm{BMI} \geq 40$ ), the relative risks of having total hip or knee replacement were, respectively, 32.73 and 8.56 times higher than non-obese people. Research suggests that obesity is not only a risk factor for OA but also may complicate recovery from joint replacement surgery. Obesity in chronic joint pain may also be related to greater consumption of analgesics. Thomazeau et $\mathrm{al}^{34}$ evaluated over 100 candidates for joint replacement of knee or hip. Obesity was related to daily consumption of analgesics, and obese patients were more likely to be taking strong opioids than normal weight patients. Time required for an operation tends to increase as BMI increases; ${ }^{35}$ compared to non-obese patients, morbidly obese patients required $18 \%$ longer time for their total knee arthroplasty. Similarly, morbid obesity appears to be related to longer hospital stay and greater postsurgical complications. . $^{36,37}$

Longitudinal studies also suggest that obesity may be a risk factor for developing chronic pain. A population-based study with over 30,000 people over $10+$ years in Norway ${ }^{38}$ suggests that obese individuals, particularly those who are inactive, have greater risk of developing chronic arm pain. A large population-based survey of over 25,450 people $^{39}$ showed that a greater number of obese people at the baseline developed low back pain 11 years later compared to those who were not obese. Similarly, another longitudinal study that followed kitchen workers in Finland ${ }^{40}$ showed that obesity was a significant risk factor ( $\mathrm{OR}=2.5,95 \% \mathrm{CI}, 1.0-6.0)$ for developing widespread pain, whereas not being obese was associated with reduction in the prevalence of multisite pain 
over time $(\mathrm{OR}=3.7,95 \% \mathrm{CI}, 1.1-12.7)$. Obesity may also contribute to the chronicity of back injury. Evaluation of people with acute work-related back injury ${ }^{41}$ revealed that obesity was one of the factors associated with persistent pain 3 months later.

Conversely, weight gain may occur as a result of chronic pain. Chronic pain is one of the major reasons that obese patients list for their weight gain. ${ }^{42}$ Frustration associated with functional limitation may lead to overeating. ${ }^{43}$ Other common adverse effects of chronic pain, such as sedentary lifestyle, poor sleep, and side effects of medications, may also contribute to weight gain in chronic pain patients. ${ }^{44-47}$

Obesity is known to have various adverse impacts on people's functional capacity and quality of life (QOL) in general. ${ }^{48}$ When obesity co-occurs with chronic pain, obesity may have further health consequence for chronic pain patients. Several studies have shown reduced life expectancy for individuals with chronic pain mostly due to cardiovascular disease. ${ }^{49-51}$ Although the exact mechanism underlying the increased mortality in chronic pain patients is not known, it has been suggested that metabolic syndrome is common in chronic pain patients, ${ }^{26,52}$ and that it may lead to compromised cardiac health. Overall, research suggests that obesity makes chronic pain more problematic in general. Obesity is related to greater physical disability and psychological distress in chronic pain patients. ${ }^{53}$ Compared to non-obese patients, obese back pain patients appear to be more functionally impaired, have greater comorbid problems, and have more radicular symptoms than non-obese counterparts. ${ }^{54,55}$

\section{Obesity and pain sensitivity}

Although research examining the relationship between obesity and subjective pain report generally shows the significant association (ie, greater prevalence of pain complaints among obese people), studies evaluating the relationship between obesity and sensitivity to experimentally induced pain in the laboratory settings have shown conflicting results both in animals and humans.

\section{Animal research}

There are some studies showing increased pain response to pressure and thermal noxious stimuli in obese rats. ${ }^{56,57}$ On the other hand, others showed no difference in pain behaviors in response to pressure or thermal stimuli ${ }^{58}$ or reduced hyperalgesic response..$^{59}$ Rossi et a ${ }^{60}$ used the operant orofacial pain method to evaluate pain behaviors in response to noxious stimulation. In this model, mice had to choose getting a reward (food) coupled with painful facial stimuli vs avoiding reward that let them avoid painful experience. Obesity was not related to the changes in their reward-seeking behaviors, suggesting that obesity may not impact pain response in the absence of inflammation or nerve injury.

Inflammatory markers were dysregulated in obese rats. Obese rats exhibited greater peripheral inflammation and hyperalgesia compared to lean rats when the rats received intradermal carrageenan injection in the paw, ${ }^{61}$ suggesting that obesity may potentiate inflammatory response. It is also possible that various neurophysiological changes that occur with weight gain, rather than, or in addition to, weight gain per se, may contribute to change in nociceptive processing. For example, Sugimoto et $\mathrm{al}^{62}$ used chemically induced diabetes in rats, which caused steady body weight gain as well as quick increases in blood glucose and hemoglobin $A_{1 c}$. Relative to nondiabetic control rats, the diabetic rats also developed mechanical and thermal hyperalgesia shortly after becoming diabetic, even when the difference in body weights was fairly modest. Thus, something other than significant weight gain may have triggered the onset of hyperalgesia in these rats.

\section{Human studies}

Earlier studies showed that obese people exhibited decreased pain threshold to electrical stimuli ${ }^{63}$ as well as mechanical stimuli. ${ }^{64}$ In fibromyalgia women, ${ }^{25}$ BMI was significantly related to the number of positive tender points (ie, painful tender points upon palpation) as well as pain rating of the tender points. Recently, Zhang et $\mathrm{al}^{65}$ tested over 2,500 healthy men for pressure pain threshold at triceps and inguinal lines. Lower threshold to triceps was associated with greater BMI and waist circumference, but the relationship was not shown for the inguinal area. Others also show inconsistent results across body parts, suggesting that the reduced pain threshold may not be present for all body areas in obesity. Miscio et $\mathrm{al}^{18}$ compared the pain thresholds between nondiabetic obese people and non-obese people in response to thermal stimuli to various fingers and the big toe. Obese people were found to have significantly lower pain thresholds to fingers than non-obese people. There was no group difference in their pain response to the big toe. Okifuji et $\mathrm{al}^{24}$ have also found that obese fibromyalgia patients reported greater pain in response to digital pressure to tender points in the lower body areas but not upper body areas relative to non-obese patients.

However, there are other studies showing results at variance. Several studies have reported reduced pain sensitivity in obese people. ${ }^{66,67}$ Price et al ${ }^{68}$ tested the sensitivity to thermal stimuli in the forehead and abdomen in obese 
and non-obese people. Obese people showed decreased sensitivity in the abdomen area but not in the forehead area. Furthermore, the groups did not differ in the central pain modulation, assessed by a temporal summation test to the forehead.

Some of the variance in the results may be related to the methodology in how noxious stimuli were delivered, such as testing sites on skin surface vs in deeper tissues. Furthermore, the discrepancy in the results in both humans and animals suggests that the relationship between obesity and pain sensitivity is not likely linear. Exact nature of the relationship between pain and obesity is not known. Each condition is a multifactorial phenomenon, likely involving several psychosocial and biological factors. Linking two such multifactorial conditions is not an easy task; however, there are several hypotheses that may link the two phenomena.

\section{Potential mechanisms underlying the obesity-pain link Mechanical and structural hypothesis}

The increased loading due to heavy weight on joints and the spine is one of the most discussed links between obesity and pain. Greater BMI is associated with greater defective change in knee cartilages ${ }^{69}$ Radiographical analyses of knee OA patients ${ }^{70}$ revealed that obese patients had a significantly lower amount of the medial and lateral compartment joint space widths than did non-obese patients. In young, non-obese individuals, joint loading and femoral cartilage thickness on walking are positively correlated; however, the relationship is not present in obese people. ${ }^{71}$

A recent study ${ }^{72}$ showed that obese individuals exert significantly greater disk compression force while lifting compared to normal weight individuals, often greatly exceeding the action limit set by the National Institute of Occupational Safety and Health. Thus, it may not be surprising to see that obesity is also related to greater structural damage in the back. Degenerative disk (DD) disorder appears to be more common in obese people. A population-based study with 2,599 Chinese individuals ${ }^{73}$ showed that although obesity was not as prevalent there, people with DD disorder had significantly greater BMI than those without DD disorder. The severity of DD was also positively correlated with BMI. Similarly, Alexiou and Voulgaris ${ }^{74}$ reported their preliminary results of significant correlation between BMI and the severity of DD in 64 patients undergoing surgery for lumbar disk herniation.

Furthermore, significantly altered body mechanics and postures are very common in obese humans, ${ }^{75}$ suggesting that such changes may be involved in the link between obesity and pain. Abnormal gait patterns are observed in obese individuals with low back pain. ${ }^{76}$ Such abnormality appears to be greater in obese pain patients than obese individuals without pain, suggesting that those with pain and obesity may recruit altered knee and ankle strategies in ambulation.

\section{Chemical mediators}

Adipose tissue is not a passive storage unit for fat cells. It is metabolically active, serving as an endocrine organ to produce and release proinflammatory cytokines and adipokins. ${ }^{77}$ Thus, obesity involves various endocrine changes. There is evidence that such endocrine changes may have a role in altered pain modulation in obesity. Research suggests that obesity may be characterized by a low-grade chronic inflammatory state as reflected by elevated levels in many inflammatory markers in the serum, such as interleukin-6 (IL-6) and C-reactive protein (CRP). ${ }^{78}$ Macrophage accumulation in adipose tissues has also been demonstrated in obese humans, ${ }^{79}$ which is known to play an important role in production and release of inflammatory mediators. ${ }^{80}$ Thus, obesity can be considered to reflect systemic inflammation which may contribute to pain. Enhanced reactivity of proinflammatory cytokines has been noted in obese people following a surgery. ${ }^{81}$ In fibromyalgia women, CRP level was significantly correlated with BMI. ${ }^{23}$ A recent population-based study ${ }^{82}$ also suggests that a high level of CRP adds a risk of having low back pain in obese people; obese people with elevated CRP level ( $>3.0 \mathrm{mg} / \mathrm{dL})$ had an OR of 2.87 (95\% CI, 1.18-6.96) of having low back pain compared to those whose CRP level was less than $3.0 \mathrm{mg} / \mathrm{dL}$, suggesting the potential mediating role of systemic inflammation in the relationship between obesity and pain.

Leptin is a hormone that signals energy intake and stores to the brain, and obesity is associated with high leptin levels. ${ }^{83}$ In end-stage OA, joint pain was significantly associated with synovial leptin level. ${ }^{84}$ Increased leptin level in OA joints was found in obese people, and when present, it seems to facilitate further inflammation and joint damage in general. ${ }^{85}$ Other obesity-related hormones and peptides, such as ghrelin and galanin, may also be involved in obesity-related change in pain perception. ${ }^{86,87}$

Recently, a role of vitamin D in obesity and chronic pain has been gaining attention. Inadequate level of vitamin D appears to be more common in obese people. ${ }^{88}$ Poor skeletal mineralization due to vitamin $\mathrm{D}$ deficiency may lead to complaints of achiness in the joints and muscles. Low level of vitamin $\mathrm{D}$ is common in people with nonspecific 
musculoskeletal pain, ${ }^{89}$ particularly in women. ${ }^{90,91}$ A recent report also found that among people with knee OA, greater proportion of obese patients had vitamin D deficiency (defined as $<20 \mathrm{ng} / \mathrm{mL}$ ), and they reported greater pain. ${ }^{92}$

\section{Depression}

High prevalence of depression has been well documented both in pain ${ }^{93}$ and obesity. ${ }^{94}$ A qualitative study ${ }^{43}$ highlights a role of depression in maintaining and potentially facilitating the comorbid pain and obesity. Decreased life reinforcement in depression and chronic pain are associated with functional limitation and craving for high-caloric foods; low self-efficacy and loss of motivation in depression also seem to promote emotional eating, with foods representing comfort. Indeed, one study ${ }^{13}$ showed diminished association between obesity and chronic pain when depression was adjusted for, suggesting the potential importance of depression in impacting the relationship between obesity and pain.

\section{Sleep}

Disturbed sleep is common in chronic pain. Estimated 53\% of chronic pain patients attending pain clinics have clinically significant insomnia, significantly greater than $3 \%$ in sexand age-matched healthy people. ${ }^{95}$ Conversely, over $40 \%$ of insomniacs in the community complain of at least one chronic pain problem. ${ }^{96}$ In animal model, chronically fragmented sleep (common in chronic pain) is known to promote obesity. ${ }^{97}$ In general, disturbed sleep appears to affect obese pain patients more significantly than non-obese pain patients. For example, obese fibromyalgia women showed a greater level of sleepiness when compared to non-obese patients, with significant positive correlation between sleepiness and BMI. ${ }^{98}$ Furthermore, sleepy women showed a greater weight gain after being diagnosed with fibromyalgia when compared to non-sleepy women. One of the common sleep disturbances in obesity is obstructive sleep apnea (OSA). The strong relationship between obesity and OSA is well documented, and the majority of those with OSA are obese. ${ }^{99}$ Chronic pain patients with sleep apnea show reduced sleep duration and poorer sleep quality than those with sleep apnea without pain. ${ }^{100} \mathrm{~A}$ large prospective study investigating the relationship between OSA and temporomandibular disorder ${ }^{101}$ showed that people with a history of OSA are more likely to develop chronic pain. A recent animal study suggests that sleep deprivation differentially impacts obese vs lean animals on pain sensitivity; when sleep was fragmented, pain threshold was increased in the lean but not in obese mice at one of the testing times during a day. ${ }^{102}$ Interestingly, successful treatment of OSA may have a positive impact on pain. A small study testing elderly OSA patients with highvs low-capacity continuous positive airway pressure (CPAP) therapy ${ }^{103}$ found that those who received high-capacity CPAP had significantly increased pain tolerance to electrical stimulation, whereas there was no change in those receiving low-capacity CPAP.

\section{Lifestyle}

Physical deactivation and deconditioning are both known risk factors for developing obesity ${ }^{104}$ and chronic pain. ${ }^{105,106}$ There are some evidence that how active a person is may mediate the relationship between obesity and pain. For example, being sedentary appeared to present increased risk of having low back pain when people are obese. ${ }^{11}$ Shiri et $\mathrm{al}^{107}$ followed 1,224 pain-free individuals over 6 years and found that obese people who stayed inactive had significantly greater chance of having back pain at the follow-up assessment compared to those who stayed active.

Our recent study shows that obese patients exhibit higher heart rate while exercising under a comparable workload relative to non-obese patients. ${ }^{24}$ Indeed, obesity is considered as a major barrier for successful physical rehabilitation. ${ }^{108}$ This suggests that obese patients may find an activating therapy more exerting and difficult, and consequently, this may impact their willingness to comply with an activation therapy. Conversely, weight management for pain patients may be complicated by the presence of chronic pain and fatigue. Comorbidity of pain and obesity often leads to a vicious cycle of pain-inactivity-obesity.

Psychological factors related to activity may also influence pain and obesity. Fear of movement is known to contribute significantly to pain and disability in chronic pain patients. ${ }^{109}$ Pain patients with high level of fear of movement tend to be less active compared to patients with low level of fear of movement. ${ }^{110}$ Recent research has demonstrated that obese pain patients tend to have greater fear of movement than non-obese pain patients, ${ }^{111,112}$ suggesting that such fear may contribute to inactivity in obese patients, which in turn adversely impacts pain and weight.

\section{Cautionary note}

The aforementioned factors are presented as the potential link between obesity and pain. However, some cautionary words need to be in place. None of these factors are likely to explain the entirety of the relationship on their own. Rather, research suggests that they are potential contributors linking obesity to pain. For example, although the assumption that 
obesity-related structural damage plays an important role in the development or maintenance of pain, the relationship between observable structural damage and pain is a tenuous one. Several researchers have noted that the radiographical findings of joints do not necessarily reflect patients' pain severity reports, ${ }^{113,114}$ suggesting that factors other than the structural issues may significantly be involved in determining how obesity impacts pain. Similarly, the exact nature of the relationship between inflammatory markers and pain is far from clear; studies have shown conflicting results with the direction and magnitude of the relationship. ${ }^{115}$ Further research is warranted to delineate how these correlates may influence the obesity, pain, and their relationship.

\section{Clinical implications Weight loss and pain reduction}

If obesity aggravates chronic pain or presents a greater risk of having pain, one may speculate that weight loss should reduce pain. Indeed, accumulated evidence seems to point in that direction. An early longitudinal observation study of approximately 800 women estimated that the risk of developing knee OA can be reduced by $50 \%$ if a person loses 5 kg. ${ }^{116}$ Similarly Larsson ${ }^{117}$ found that following a weight loss dieting program, people lost on average $14 \%$ of their pretreatment weight and that their reports of musculoskeletal pain significantly improved. Vincent et $\mathrm{al}^{118}$ reported a case-control study in which 25 morbidly obese people who underwent bariatric surgery were compared to 20 sex- and weight-matched controls (ie, no surgery). On average, the patients in the surgery group lost $19.4 \mathrm{~kg}$ and $5.2 \%$ of body fat at the 3-month follow-up. They also reported significant reduction in pain in the low back and knee, whereas control subjects who did not receive the surgery did not report change in their pain levels.

Weight loss appears to help obese chronic pain patients as well. A case series observation ${ }^{119}$ reports significantly reduced headache frequency and related disability following bariatric surgery. Out of 105 women who were admitted for bariatric surgery, 29 patients had preexisting migraine headaches. These patients were not different from non-migraine patients in terms of their demographics and obesity-related health characteristics. Migraine frequency was on average 6.0 per month before the surgery and 1.0 per month at the 6-month follow-up. Similarly, Khoueir et al ${ }^{120}$ followed 38 morbidly obese people with a history of chronic back pain undergoing bariatric surgery. The mean preoperative BMI was 52.3, which was decreased by $26.7 \%$ postoperative and by $27 \%$ at 12-month follow-up. The Visual Analog Scale (VAS) pain scores for low back were 5.2 at preoperative and 2.9 at postoperative. At the year of follow-up, $68 \%$ of the patients reported improvement in pain. They also showed significant decrease in the self-reported back pain-related disability at the postoperative assessment.

Nonsurgical weight management programs, although they generally produce much less weight loss than surgery, also show strong beneficial effects on chronic pain. Multiple reports show that weight management programs involving diet and exercise help OA patients lose weight and improve their symptoms, ${ }^{121-123}$ even for people with advanced age ( $\geq 75$ years old). ${ }^{124}$ Similarly, weight loss appears to help people with diffuse, generalized pain as well. Several cases of improvement in fibromyalgia symptoms following weight loss have been reported. ${ }^{125}$ In another study, a 3-month vegan diet open trial resulted in significant weight loss and symptomatic improvement, but both weight and symptoms returned to the baseline after participants resumed a regular diet. ${ }^{126}$ In an uncontrolled behavioral weight loss treatment trial, fibromyalgia patients showed a $4.4 \%$ weight loss, accompanied by symptom reduction. ${ }^{127}$ A recent randomized study ${ }^{128}$ showed that those patients who underwent a 6-month diet-based weight management program had significantly greater reduction in hyperalgesia and improvement in the QOL.

It is important to note that many weight loss programs include a diet and exercise or activation components; thus, factors beyond simple loss of fat mass may contribute to the change in their pain condition. For example, a recent study ${ }^{20}$ highlighted the role that the muscle mass may play in musculoskeletal pain. Since weight loss without activation may lead to a loss of muscle mass as well, future studies may need to specifically investigate the impact of developing muscle mass via exercise within a weight loss program on changing pain sensitivity or pain complaints.

Another important yet less understood issue is how to maintain the weight loss and its benefit. Relapse and weight regain several years after obesity surgery are common. ${ }^{129,130}$ Long-term success of bariatric surgery seems to depend on patients' adaptive coping with functioning and eating. ${ }^{131}$ Behaviorally oriented weight management programs tend to produce a smaller degree of weight loss compared to surgery. However, these programs are typically developed on the basis of helping people internalize new and adaptive habit of eating and exercising. Nonetheless, as is the case with surgery, the long-term success of these programs appears rather modest. Whereas some people may be able to maintain the initial weight loss, the majority of people appear to regain some weight following such a program. ${ }^{132}$ 
Increased attention has recently been given to a lifestyle modification program in which program participants are encouraged to accumulate moderate-intensity physical activity through increasing behavioral skills and by incorporating short bouts of activities into their daily routines, rather than formal exercise program. Examples of such activities include increasing walking, using stairs, and doing a little extra household chores and yard work. Dunn et al ${ }^{133}$ show that sedentary adults undergoing a lifestyle modification program showed improvement in physical fitness and blood pressure comparable to those who underwent the traditional, structured physical exercise program. Similarly, lifestyle modification with increased daily physical activities and dietary education has resulted in health benefit by reducing weight and improving blood pressure and lipid levels comparable to a traditional aerobic exercise program in obese women. ${ }^{134}$ There has not been much research testing this type of intervention in chronic pain; however, a recent pilot study using the e-health platform to improve diet and mobility has shown significant benefit of weight loss and symptom improvement in obese people with lumbar spinal stenosis. ${ }^{135}$

\section{Summary and future direction}

Obesity and chronic pain both present serious public health concerns. The two conditions appear to co-occur frequently and likely have reciprocally negative impact on one another. Although as clinical syndromes, pain and obesity are significantly associated with each other, research evaluating the relationship between obesity and pain sensitivity has yielded conflicting results. This suggests that the relationship between obesity and pain is not a direct one but is mediated by various factors. Such factors include biomechanical/ structural changes associated with obesity, inflammatory mediators, mood disturbance, poor sleep, and lifestyle issues. In particular, research on potential chemical mediators linking obesity with pain is rapidly growing. Those interested in further discussion on this topic may be interested in excellent reviews recently published. ${ }^{115,136}$ These papers also address various potential mediators relevant to specific pain diagnoses as well. It is, however, important to note that all of these mediating factors are implicated in the obesity-pain link in diverse ways across patients; that is, the relevance of these factors may vary greatly from a person to person. Multivariate assessment of patients and consolidation of all relevant biopsychosocial information are essential in understanding how obesity and chronic pain are intertwined in each patient.

In general, losing weight, either via surgical intervention or via behavioral intervention (ie, diet and exercise), appears to be beneficial for pain and associated QOL. A challenge however seems to be the long-term maintenance of benefit. All treatments require patients to internalize adaptive eating habits and staying active, which are not easy tasks even for healthy people. Further research is needed to develop posttreatment strategies to help patients maintain weight loss.

\section{Disclosure}

The authors report no conflicts of interest in this work.

\section{References}

1. Garrow J. Obesity and Related Diseases. London: Churchill Livingstone; 1981.

2. World Health Organization. Obesity and Overweight: Fact Sheet No 311;2015. Available from: http://www.who.int/mediacentre/factsheets/ fs311/en/\#. Accessed April 1, 2015.

3. Ogden CL, Carroll MD, Kit BK, Flegal KM. Prevalence of childhood and adult obesity in the United States, 2011-2012. JAMA. 2014;311(8):806-814.

4. Guh DP, Zhang W, Bansback N, Amarsi Z, Birmingham CL, Anis AH. The incidence of co-morbidities related to obesity and overweight: a systematic review and meta-analysis. BMC Public Health. 2009;9:88.

5. Cawley J, Meyerhoefer C. The medical care costs of obesity: an instrumental variables approach. J Health Econ. 2012;31(1):219-230.

6. Higgins DM, Kerns RD, Brandt CA, et al. Persistent pain and comorbidity among operation enduring freedom/operation Iraqi freedom/ operation New Dawn veterans. Pain Med. 2014;15(5):782-790.

7. Deere KC, Clinch J, Holliday K, et al. Obesity is a risk factor for musculoskeletal pain in adolescents: findings from a population-based cohort. Pain. 2012;153(9):1932-1938.

8. Hoftun GB, Romundstad PR, Rygg M. Factors associated with adolescent chronic non-specific pain, chronic multisite pain, and chronic pain with high disability: the Young-HUNT Study 2008. J Pain. 2012;13(9):874-883.

9. Smith SM, Sumar B, Dixon KA. Musculoskeletal pain in overweight and obese children. Int J Obes (Lond). 2014;38(1):11-15.

10. Hitt HC, McMillen RC, Thornton-Neaves T, Koch K, Cosby AG. Comorbidity of obesity and pain in a general population: results from the Southern Pain Prevalence Study. J Pain. 2007;8(5):430-436.

11. Smuck M, Kao MC, Brar N, Martinez-Ith A, Choi J, Tomkins-Lane CC. Does physical activity influence the relationship between low back pain and obesity? Spine J. 2014;14(2):209-216.

12. Stone AA, Broderick JE. Obesity and pain are associated in the United States. Obesity (Silver Spring). 2012;20(7):1491-1495.

13. Wright LJ, Schur E, Noonan C, Ahumada S, Buchwald D, Afari N. Chronic pain, overweight, and obesity: findings from a communitybased twin registry. J Pain. 2010;11(7):628-635.

14. McCarthy LH, Bigal ME, Katz M, Derby C, Lipton RB. Chronic pain and obesity in elderly people: results from the Einstein aging study. J Am Geriatr Soc. 2009;57(1):115-119.

15. Chai NC, Scher AI, Moghekar A, Bond DS, Peterlin BL. Obesity and headache: part I - a systematic review of the epidemiology of obesity and headache. Headache. 2014;54(2):219-234.

16. Eslick GD. Gastrointestinal symptoms and obesity: a meta-analysis. Obes Rev. 2012;13(5):469-479.

17. Gurian MB, Mitidieri AM, da Silva JB, et al. Measurement of pain and anthropometric parameters in women with chronic pelvic pain. $J$ Eval Clin Pract. 2015;21(1):21-27.

18. Miscio G, Guastamacchia G, Brunani A, Priano L, Baudo S, Mauro A. Obesity and peripheral neuropathy risk: a dangerous liaison. J Peripher Nerv Syst. 2005;10(4):354-358.

19. Ohayon MM, Stingl JC. Prevalence and comorbidity of chronic pain in the German general population. J Psychiatr Res. 2012;46(4):444-450. 
20. Yoo JJ, Cho NH, Lim SH, Kim HA. Relationships between body mass index, fat mass, muscle mass, and musculoskeletal pain in community residents. Arthritis Rheumatol. 2014;66(12):3511-3520.

21. Yunus MB, Arslan S, Aldag JC. Relationship between body mass index and fibromyalgia features. Scand J Rheumatol. 2002;31(1):27-31.

22. Elert J, Kendall SA, Larsson B, Mansson B, Gerdle B. Chronic pain and difficulty in relaxing postural muscles in patients with fibromyalgia and chronic whiplash associated disorders. J Rheumatol. 2001;28(6):1361-1368.

23. Okifuji A, Bradshaw DH, Olson C. Evaluating obesity in fibromyalgia: neuroendocrine biomarkers, symptoms, and functions. Clin Rheumatol. 2009;28(4):475-478.

24. Okifuji A, Donaldson GW, Barck L, Fine PG. Relationship between fibromyalgia and obesity in pain, function, mood, and sleep. J Pain. 2010;11(12):1329-1337.

25. Neumann L, Lerner E, Glazer Y, Bolotin A, Shefer A, Buskila D. A cross-sectional study of the relationship between body mass index and clinical characteristics, tenderness measures, quality of life, and physical functioning in fibromyalgia patients. Clin Rheumatol. 2008;27(12):1543-1547.

26. Loevinger BL, Muller D, Alonso C, Coe CL. Metabolic syndrome in women with chronic pain. Metabolism. 2007;56(1):87-93.

27. Lawrence RC, Felson DT, Helmick CG, et al; National Arthritis Data Workgroup. Estimates of the prevalence of arthritis and other rheumatic conditions in the United States. Part II. Arthritis Rheum. 2008;58(1):26-35.

28. Reijman M, Pols HA, Bergink AP, et al. Body mass index associated with onset and progression of osteoarthritis of the knee but not of the hip: the Rotterdam Study. Ann Rheum Dis. 2007;66(2):158-162.

29. Lohmander LS, Gerhardsson de Verdier M, Rollof J, Nilsson PM, Engstrom G. Incidence of severe knee and hip osteoarthritis in relation to different measures of body mass: a population-based prospective cohort study. Ann Rheum Dis. 2009;68(4):490-496.

30. Lee S, Kim TN, Kim SH. Sarcopenic obesity is more closely associated with knee osteoarthritis than is nonsarcopenic obesity: a cross-sectional study. Arthritis Rheum. 2012;64(12):3947-3954.

31. Lee R, Kean WF. Obesity and knee osteoarthritis. Inflammopharmacology. 2012;20(2):53-58.

32. Losina E, Thornhill TS, Rome BN, Wright J, Katz JN. The dramatic increase in total knee replacement utilization rates in the United States cannot be fully explained by growth in population size and the obesity epidemic. J Bone Joint Surg Am. 2012;94(3):201-207.

33. Bourne R, Mukhi S, Zhu N, Keresteci M, Marin M. Role of obesity on the risk for total hip or knee arthroplasty. Clin Orthop Relat Res. 2007;465:185-188.

34. Thomazeau J, Perin J, Nizard R, et al. Pain management and pain characteristics in obese and normal weight patients before joint replacement. J Eval Clin Pract. 2014;20(5):611-616.

35. Liabaud B, Patrick DA Jr, Geller JA. Higher body mass index leads to longer operative time in total knee arthroplasty. J Arthroplasty. 2013;28(4):563-565.

36. Rajgopal R, Martin R, Howard JL, Somerville L, MacDonald SJ, Bourne R. Outcomes and complications of total hip replacement in super-obese patients. Bone Joint J. 2013;95-B(6):758-763.

37. Schwarzkopf R, Thompson SL, Adwar SJ, Liublinska V, Slover JD. Postoperative complication rates in the "super-obese" hip and knee arthroplasty population. J Arthroplasty. 2012;27(3):397-401.

38. Mork PJ, Holtermann A, Nilsen TI. Physical exercise, body mass index and risk of chronic arm pain: longitudinal data on an adult population in Norway. Eur J Pain. 2013;17(8):1252-1258.

39. Heuch I, Heuch I, Hagen K, Zwart JA. Body mass index as a risk factor for developing chronic low back pain: a follow-up in the Nord-Trondelag Health Study. Spine (Phila Pa 1976). 2013;38(2):133-139.

40. Haukka E, Ojajarvi A, Takala EP, Viikari-Juntura E, Leino-Arjas P. Physical workload, leisure-time physical activity, obesity and smoking as predictors of multisite musculoskeletal pain. A 2-year prospective study of kitchen workers. Occup Environ Med. 2012;69(7):485-492.
41. Fransen M, Woodward M, Norton R, Coggan C, Dawe M, Sheridan N. Risk factors associated with the transition from acute to chronic occupational back pain. Spine (Phila Pa 1976). 2002;27(1):92-98.

42. Ferguson S, Al-Rehany L, Tang C, Gougeon L, Warwick K, Madill J. Self-reported causes of weight gain: among prebariatric surgery patients. Can J Diet Pract Res. 2013;74(4):189-192.

43. Janke AE, Kozak AT. "The more pain I have, the more I want to eat": obesity in the context of chronic pain. Obesity (Silver Spring). 2012; 20(10):2027-2034.

44. Smith HS, Elliott JA. Opioid-induced androgen deficiency (OPIAD). Pain Physician. 2012;15(3 Suppl):ES145-ES156.

45. Tzellos TG, Toulis KA, Goulis DG, et al. Gabapentin and pregabalin in the treatment of fibromyalgia: a systematic review and a meta-analysis. J Clin Pharm Ther. 2010;35(6):639-656.

46. Jebb SA, Moore MS. Contribution of a sedentary lifestyle and inactivity to the etiology of overweight and obesity: current evidence and research issues. Med Sci Sports Exerc. 1999;31(11 Suppl):S534-S541.

47. Knutson KL, Van Cauter E. Associations between sleep loss and increased risk of obesity and diabetes. Ann NY Acad Sci. 2008;1129:287-304.

48. Forhan M, Gill SV. Obesity, functional mobility and quality of life. Best Pract Res Clin Endocrinol Metab. 2013;27(2):129-137.

49. Torrance N, Elliott AM, Lee AJ, Smith BH. Severe chronic pain is associated with increased 10 year mortality. A cohort record linkage study. Eur J Pain. 2010;14(4):380-386.

50. McBeth J, Symmons DP, Silman AJ, et al. Musculoskeletal pain is associated with a long-term increased risk of cancer and cardiovascularrelated mortality. Rheumatology (Oxford). 2009;48(1):74-77.

51. Andersson HI. Increased mortality among individuals with chronic widespread pain relates to lifestyle factors: a prospective populationbased study. Disabil Rehabil. 2009;31(24):1980-1987.

52. Goodson NJ, Smith BH, Hocking LJ, et al; Generation Scotland. Cardiovascular risk factors associated with the metabolic syndrome are more prevalent in people reporting chronic pain: results from a crosssectional general population study. Pain. 2013;154(9):1595-1602.

53. Marcus DA. Obesity and the impact of chronic pain. Clin J Pain. 2004; 20(3):186-191.

54. Fanuele JC, Abdu WA, Hanscom B, Weinstein JN. Association between obesity and functional status in patients with spine disease. Spine (Phila Pa 1976). 2002;27(3):306-312.

55. Hagen KB, Tambs K, Bjerkedal T. A prospective cohort study of risk factors for disability retirement because of back pain in the general working population. Spine (Phila Pa 1976). 2002;27(16):1790-1796.

56. Roane DS, Porter JR. Nociception and opioid-induced analgesia in lean (Fa/-) and obese (fa/fa) Zucker rats. Physiol Behav. 1986;38(2): 215-218.

57. Zhuang HX, Wuarin L, Fei ZJ, Ishii DN. Insulin-like growth factor (IGF) gene expression is reduced in neural tissues and liver from rats with non-insulin-dependent diabetes mellitus, and IGF treatment ameliorates diabetic neuropathy. J Pharmacol Exp Ther. 1997;283(1):366-374.

58. Croci T, Zarini E. Effect of the cannabinoid CB1 receptor antagonist rimonabant on nociceptive responses and adjuvant-induced arthritis in obese and lean rats. Br J Pharmacol. 2007;150(5):559-566.

59. Ramzan I, Wong BK, Corcoran GB. Pain sensitivity in dietary-induced obese rats. Physiol Behav. 1993;54(3):433-435.

60. Rossi HL, Luu AK, Kothari SD, et al. Effects of diet-induced obesity on motivation and pain behavior in an operant assay. Neuroscience. 2013;235:87-95.

61. Iannitti T, Graham A, Dolan S. Increased central and peripheral inflammation and inflammatory hyperalgesia in Zucker rat model of leptin receptor deficiency and genetic obesity. Exp Physiol. 2012;97(11): $1236-1245$.

62. Sugimoto K, Rashid IB, Kojima K, et al. Time course of pain sensation in rat models of insulin resistance, type 2 diabetes, and exogenous hyperinsulinaemia. Diabetes Metab Res Rev. 2008;24(8):642-650.

63. Pradalier A, Willer JC, Boureau F, Dry J. Relationship between pain and obesity: an electrophysiological study. Physiol Behav. 1981;27(6): 961-964. 
64. McKendall MJ, Haier RJ. Pain sensitivity and obesity. Psychiatry Res. 1983;8(2):119-125.

65. Zhang Y, Zhang S, Gao Y, et al. Factors associated with the pressure pain threshold in healthy Chinese men. Pain Med. 2013;14(9):1291-1300.

66. Dodet P, Perrot S, Auvergne L, et al. Sensory impairment in obese patients? Sensitivity and pain detection thresholds for electrical stimulation after surgery-induced weight loss, and comparison with a nonobese population. Clin J Pain. 2013;29(1):43-49.

67. Zahorska-Markiewicz B, Kucio C, Pyszkowska J. Obesity and pain. Hum Nutr Clin Nutr. 1983;37(4):307-310.

68. Price RC, Asenjo JF, Christou NV, Backman SB, Schweinhardt P. The role of excess subcutaneous fat in pain and sensory sensitivity in obesity. Eur J Pain. 2013;17(9):1316-1326.

69. Ding C, Cicuttini F, Scott F, Cooley H, Jones G. Knee structural alteration and BMI: a cross-sectional study. Obes Res. 2005;13(2):350-361.

70. Cimen OB, Incel NA, Yapici Y, Apaydin D, Erdogan C. Obesity related measurements and joint space width in patients with knee osteoarthritis. Ups J Med Sci. 2004;109(2):159-164.

71. Blazek K, Favre J, Asay J, Erhart-Hledik J, Andriacchi T. Age and obesity alter the relationship between femoral articular cartilage thickness and ambulatory loads in individuals without osteoarthritis. $J$ Orthop Res. 2014;32(3):394-402.

72. Singh D, Park W, Hwang D, Levy MS. Severe obesity effect on low back biomechanical stress of manual load lifting. Work. Epub September 23, 2014.

73. Samartzis D, Karppinen J, Chan D, Luk KD, Cheung KM. The association of lumbar intervertebral disc degeneration on magnetic resonance imaging with body mass index in overweight and obese adults: a populationbased study. Arthritis Rheum. 2012;64(5):1488-1496.

74. Alexiou GA, Voulgaris S. Body mass index and lumbar disc degeneration. Pain Med. 2013;14(2):313.

75. Fabris de Souza SA, Faintuch J, Valezi AC, et al. Postural changes in morbidly obese patients. Obes Surg. 2005;15(7):1013-1016.

76. Cimolin V, Vismara L, Galli M, Zaina F, Negrini S, Capodaglio P. Effects of obesity and chronic low back pain on gait. J Neuroeng Rehabil. 2011;8:55.

77. Ronti T, Lupattelli G, Mannarino E. The endocrine function of adipose tissue: an update. Clin Endocrinol (Oxf). 2006;64(4):355-365.

78. Bluher M, Fasshauer M, Tonjes A, Kratzsch J, Schon MR, Paschke R. Association of interleukin-6, C-reactive protein, interleukin-10 and adiponectin plasma concentrations with measures of obesity, insulin sensitivity and glucose metabolism. Exp Clin Endocrinol Diabetes. 2005;113(9):534-537.

79. Weisberg SP, McCann D, Desai M, Rosenbaum M, Leibel RL, Ferrante AW Jr. Obesity is associated with macrophage accumulation in adipose tissue. J Clin Invest. 2003;112(12):1796-1808.

80. Wellen KE, Hotamisligil GS. Obesity-induced inflammatory changes in adipose tissue. J Clin Invest. 2003;112(12):1785-1788.

81. Motaghedi R, Bae JJ, Memtsoudis SG, et al. Association of obesity with inflammation and pain after total hip arthroplasty. Clin Orthop Relat Res. 2014;472(5):1442-1448.

82. Briggs MS, Givens DL, Schmitt LC, Taylor CA. Relations of C-reactive protein and obesity to the prevalence and the odds of reporting low back pain. Arch Phys Med Rehabil. 2013;94(4):745-752. Epub November 24, 2012.

83. Considine RV. Human leptin: an adipocyte hormone with weight-regulatory and endocrine functions. Semin Vasc Med. 2005;5(1):15-24.

84. Lübbeke A, Finckh A, Puskas GJ, et al. Do synovial leptin levels correlate with pain in end stage arthritis? Int Orthop. 2013;37(10): 2071-2079.

85. Vuolteenaho K, Koskinen A, Moilanen E. Leptin - a link between obesity and osteoarthritis. Applications for prevention and treatment. Basic Clin Pharmacol Toxicol. 2014;114(1):103-108.

86. Guneli E, Gumustekin M, Ates M. Possible involvement of ghrelin on pain threshold in obesity. Med Hypotheses. 2010;74(3):452-454.

87. Yu M, Fang P, Shi M, et al. Galanin receptors possibly modulate the obesity-induced change in pain threshold. Peptides. 2013;44:55-59.
88. Pereira-Santos M, Costa PR, Assis AM, Santos CA, Santos DB. Obesity and vitamin D deficiency: a systematic review and meta-analysis. Obes Rev. 2015;16(4):341-349.

89. Plotnikoff GA, Quigley JM. Prevalence of severe hypovitaminosis D in patients with persistent, nonspecific musculoskeletal pain. Mayo Clin Proc. 2003;78(12):1463-1470.

90. Heidari B, Shirvani JS, Firouzjahi A, Heidari P, Hajian-Tilaki KO. Association between nonspecific skeletal pain and vitamin D deficiency. Int J Rheum Dis. 2010;13(4):340-346.

91. Hicks GE, Shardell M, Miller RR, et al. Associations between vitamin D status and pain in older adults: the Invecchiare in Chianti study. J Am Geriatr Soc. 2008;56(5):785-791.

92. Glover TL, Goodin BR, King CD, et al. A Cross-sectional examination of vitamin D, obesity, and measures of pain and function in middleaged and older adults with knee osteoarthritis. Clin J Pain. Epub January 7, 2015.

93. Okifuji A, Turk DC. Chronic pain and depression: vulnerability and resilience. In: Flaten MA, al'Absi M, editors. Neuroscience of Pain, Stress, and Emotion. New York, NY: Elsevier; In press 2015.

94. Pratt LA, Brody DJ. Depression and obesity in the US adult household population, 2005-2010. NCHS Data Brief. 2014;167:1-8.

95. Tang NK, Wright KJ, Salkovskis PM. Prevalence and correlates of clinical insomnia co-occurring with chronic back pain. J Sleep Res. 2007;16(1):85-95.

96. Ohayon MM. Relationship between chronic painful physical condition and insomnia. J Psychiatr Res. 2005;39(2):151-159.

97. Wang Y, Carreras A, Lee S, et al. Chronic sleep fragmentation promotes obesity in young adult mice. Obesity (Silver Spring). 2014; 22(3):758-762.

98. de Araujo TA, Mota MC, Crispim CA. Obesity and sleepiness in women with fibromyalgia. Rheumatol Int. 2015;35(2):281-287.

99. Badran M, Ayas N, Laher I. Insights into obstructive sleep apnea research. Sleep Med. 2014;15(5):485-495.

100. Nadeem R, Bawaadam H, Asif A, et al. Effect of musculoskeletal pain on sleep architecture in patients with obstructive sleep apnea. Sleep Breath. 2014;18(3):571-577.

101. Sanders AE, Essick GK, Fillingim R, et al. Sleep apnea symptoms and risk of temporomandibular disorder: OPPERA cohort. J Dent Res. 2013;92(7 Suppl):70S-77S.

102. He J, Kastin AJ, Wang Y, Pan W. Sleep fragmentation has differential effects on obese and lean mice. J Mol Neurosci. 2015;55(3):644-652.

103. Onen SH, Onen F, Albrand G, Decullier E, Chapuis F, Dubray C. Pain tolerance and obstructive sleep apnea in the elderly. $\mathrm{J} \mathrm{Am} \mathrm{Med}$ Dir Assoc. 2010;11(9):612-616.

104. Wareham NJ, van Sluijs EM, Ekelund U. Physical activity and obesity prevention: a review of the current evidence. Proc Nutr Soc. 2005; 64(2):229-247.

105. Stroyer J, Jensen LD. The role of physical fitness as risk indicator of increased low back pain intensity among people working with physically and mentally disabled persons: a 30 -month prospective study. Spine (Phila Pa 1976). 2008;33(5):546-554.

106. Deyo RA, Bass JE. Lifestyle and low-back pain. The influence of smoking and obesity. Spine (Phila Pa 1976). 1989;14(5):501-506.

107. Shiri R, Solovieva S, Husgafvel-Pursiainen K, et al. The role of obesity and physical activity in non-specific and radiating low back pain: the Young Finns study. Semin Arthritis Rheum. 2013;42(6):640-650.

108. Jerant AF, von Friederichs-Fitzwater MM, Moore M. Patients' perceived barriers to active self-management of chronic conditions. Patient Educ Couns. 2005;57(3):300-307.

109. Vlaeyen JW, Linton SJ. Fear-avoidance and its consequences in chronic musculoskeletal pain: a state of the art. Pain. 2000;85(3):317-332.

110. Koho P, Orenius T, Kautiainen H, Haanpaa M, Pohjolainen T, Hurri H. Association of fear of movement and leisure-time physical activity among patients with chronic pain. $J$ Rehabil Med. 2011;43(9):794-799.

111. Vincent HK, Lamb KM, Day TI, Tillman SM, Vincent KR, George SZ. Morbid obesity is associated with fear of movement and lower quality of life in patients with knee pain-related diagnoses. $P M R$. 2010;2(8):713-722. 
112. Vincent HK, Omli MR, Day T, Hodges M, Vincent KR, George SZ. Fear of movement, quality of life, and self-reported disability in obese patients with chronic lumbar pain. Pain Med. 2011;12(1):154-164.

113. Blankenbaker DG, Ullrick SR, Davis KW, De Smet AA, Haaland B, Fine JP. Correlation of MRI findings with clinical findings of trochanteric pain syndrome. Skeletal Radiol. 2008;37(10):903-909.

114. Link TM, Steinbach LS, Ghosh S, et al. Osteoarthritis: MR imaging findings in different stages of disease and correlation with clinical findings. Radiology. 2003;226(2):373-381.

115. DeVon HA, Piano MR, Rosenfeld AG, Hoppensteadt DA. The association of pain with protein inflammatory biomarkers: a review of the literature. Nurs Res. 2014;63(1):51-62.

116. Felson DT, Zhang Y, Anthony JM, Naimark A, Anderson JJ. Weight loss reduces the risk for symptomatic knee osteoarthritis in women. The Framingham Study. Ann Intern Med. 1992;116(7):535-539.

117. Larsson UE. Influence of weight loss on pain, perceived disability and observed functional limitations in obese women. Int J Obes Relat Metab Disord. 2004;28(2):269-277.

118. Vincent HK, Ben-David K, Conrad BP, Lamb KM, Seay AN, Vincent KR. Rapid changes in gait, musculoskeletal pain, and quality of life after bariatric surgery. Surg Obes Relat Dis. 2012;8(3):346-354.

119. Novack V, Fuchs L, Lantsberg L, et al. Changes in headache frequency in premenopausal obese women with migraine after bariatric surgery: a case series. Cephalalgia. 2011;31(13):1336-1342.

120. Khoueir P, Black MH, Crookes PF, Kaufman HS, Katkhouda N, Wang MY. Prospective assessment of axial back pain symptoms before and after bariatric weight reduction surgery. Spine J. 2009;9(6): $454-463$.

121. Messier SP, Mihalko SL, Legault C, et al. Effects of intensive diet and exercise on knee joint loads, inflammation, and clinical outcomes among overweight and obese adults with knee osteoarthritis: the IDEA randomized clinical trial. JAMA. 2013;310(12):1263-1273.

122. Lim JY, Tchai E, Jang SN. Effectiveness of aquatic exercise for obese patients with knee osteoarthritis: a randomized controlled trial. PMR. 2010;2(8):723-731. [quiz 793].

123. Bliddal H, Leeds AR, Stigsgaard L, Astrup A, Christensen R. Weight loss as treatment for knee osteoarthritis symptoms in obese patients: 1-year results from a randomised controlled trial. Ann Rheum Dis. 2011;70(10):1798-1803.

124. Quintrec JL, Verlhac B, Cadet C, et al. Physical exercise and weight loss for hip and knee osteoarthritis in very old patients: a systematic review of the literature. Open Rheumatol J. 2014;8:89-95.
125. Deodhar AA, Fisher RA, Blacker CV, Woolf AD. Fluid retention syndrome and fibromyalgia. Br J Rheumatol. 1994;33(6):576-582.

126. Kaartinen K, Lammi K, Hypen M, Nenonen M, Hanninen O, Rauma AL. Vegan diet alleviates fibromyalgia symptoms. Scand J Rheumatol. 2000;29(5):308-313.

127. Shapiro JR, Anderson DA, Danoff-Burg S. A pilot study of the effects of behavioral weight loss treatment on fibromyalgia symptoms. J Psychosom Res. 2005;59(5):275-282.

128. Senna MK, Sallam RA, Ashour HS, Elarman M. Effect of weight reduction on the quality of life in obese patients with fibromyalgia syndrome: a randomized controlled trial. Clin Rheumatol. 2012; 31(11):1591-1597.

129. Magro DO, Geloneze B, Delfini R, Pareja BC, Callejas F, Pareja JC. Long-term weight regain after gastric bypass: a 5-year prospective study. Obes Surg. 2008;18(6):648-651.

130. Sjöström L, Narbro K, Sjöström CD, et al; Swedish Obese Subjects Study. Effects of bariatric surgery on mortality in Swedish obese subjects. N Engl J Med. 2007;357(8):741-752.

131. Wood KV, Ogden J. Patients' long-term experiences following obesity surgery with a focus on eating behaviour: a qualitative study. $J$ Health Psychol. Epub April 13, 2015.

132. Wing RR, Phelan S. Long-term weight loss maintenance. Am J Clin Nutr. 2005;82(1 Suppl):222S-225S

133. Dunn AL, Marcus BH, Kampert JB, Garcia ME, Kohl HW 3rd, Blair SN. Comparison of lifestyle and structured interventions to increase physical activity and cardiorespiratory fitness: a randomized trial. JAMA. 1999;281(4):327-334.

134. Andersen RE, Wadden TA, Bartlett SJ, Zemel B, Verde TJ, Franckowiak SC. Effects of lifestyle activity vs structured aerobic exercise in obese women: a randomized trial. JAMA. 1999;281(4): 335-340

135. Tomkins-Lane CC, Lafave LM, Parnell JA, et al. The spinal stenosis pedometer and nutrition lifestyle intervention (SSPANLI): development and pilot. Spine J. 2015;15(4):577-586.

136. Arranz LI, Rafecas M, Alegre C. Effects of obesity on function and quality of life in chronic pain conditions. Curr Rheumatol Rep. 2014;16(1):390.
Journal of Pain Research

\section{Publish your work in this journal}

The Journal of Pain Research is an international, peer-reviewed, open access, online journal that welcomes laboratory and clinical findings in the fields of pain research and the prevention and management of pain. Original research, reviews, symposium reports, hypothesis formation and commentaries are all considered for publication.

\section{Dovepress}

The manuscript management system is completely online and includes a very quick and fair peer-review system, which is all easy to use. Visit http://www.dovepress.com/testimonials.php to read real quotes from published authors. 